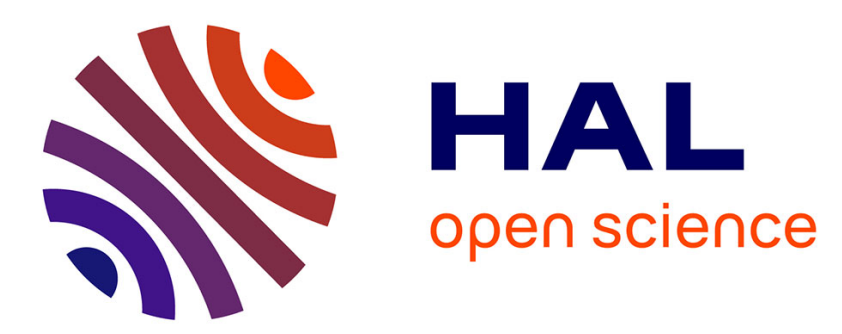

\title{
Effect of anthropometry scaling on the response of the piper child scalable human body model subject to pelvic impact
}

Marie-Christine Chevalier, Philippe Beillas

\section{- To cite this version:}

Marie-Christine Chevalier, Philippe Beillas. Effect of anthropometry scaling on the response of the piper child scalable human body model subject to pelvic impact. Journal of Biomechanics, 2020, 25 p. 10.1016/j.jbiomech.2020.109757 . hal-02566551

\section{HAL Id: hal-02566551 \\ https://hal.science/hal-02566551}

Submitted on 7 May 2020

HAL is a multi-disciplinary open access archive for the deposit and dissemination of scientific research documents, whether they are published or not. The documents may come from teaching and research institutions in France or abroad, or from public or private research centers.
L'archive ouverte pluridisciplinaire HAL, est destinée au dépôt et à la diffusion de documents scientifiques de niveau recherche, publiés ou non, émanant des établissements d'enseignement et de recherche français ou étrangers, des laboratoires publics ou privés. 
CHEVALIER, Marie-Christine, BEILLAS, Philippe, 2020, Effect of anthropometry scaling on the response of the piper child scalable human body model subject to pelvic impact, Journal of Biomechanics, Elsevier, 25 p, DOI: 10.1016/j.jbiomech.2020.109757

1 EFFECT OF ANTHROPOMETRY SCALING ON THE RESPONSE OF THE PIPER CHILD 2 SCALABLE HUMAN BODY MODEL SUBJECT TO PELVIC IMPACT

3 Marie-Christine Chevalier, Philippe Beillas

4 Univ Lyon, Université Claude Bernard Lyon 1, Univ Gustave Eiffel, IFSTTAR, LBMC UMR_T 9406, F5 69622, Lyon, France

6 Corresponding Author: Marie-Christine Chevalier

7 Address: Laboratoire de Biomécanique et Mécanique des Chocs,

8 Université Eiffel - IFSTTAR,

9 25, avenue François Mitterrand,

10 Case24

11 Cité des mobilités

12 F-69675 Bron Cedex

13 Phone : +33 4721323 62,

E-mail : marie-christine.chevalier@univ-eiffel.fr

Keywords

17 Human Body Model - Finite Elements - Anthropometry - Scalable Model - Side Impact

18 Work submitted as an Original Article

19 Word count: 3029 words (Introduction through Conclusion) 
The Open Source PIPER child scalable human body model was publicly released in April 2017 (www.piperproject.org) along with frontal and side impact validation conditions. The objective of this paper is to investigate the effect of anthropometry scaling on the response of the model in side pelvic impact.

Three setups from two published studies were used: (1) a lateral drop test (2) a greater trochanter impact with a rigid pendulum (3) a pelvis side impact with a flat surface. The first study used scaling assumption developed for crash test dummy design (setups 1 and 2) and the second performed tests on post mortem human surrogates. The baseline 6 years old child model was scaled using a model morphing methodology to match the stature and weight of the surrogates used in the two published studies.

Overall, the main trends observed in the three setups can be approached using the baseline model. Although the model morphing did not account for specific skeletal dimensions, it reduced some of the discrepancies between model response and reference for the drop test and flat plate impact. However, it had little effect on the pendulum test. In that case, the model response was in the corridor at low speed but above at higher speeds. Possible reasons for this difference should be further investigated.

\section{Introduction}

Human Body Models (HBMs) have the potential to provide significant insight into the pediatric response to impact in case of motor vehicle accident. The PIPER child scalable finite element model (Beillas et al., 2016) was publicly released under an Open Source license in April 2017 (www.piper-project.org). The model is scalable as a function of stature/age within the PIPER software (also available at www.piper-project.org). Several applications were performed in frontal impact with the PIPER model (Giordano et al., 2017) or a previous version (Beillas et al., 2014). In side impact, reference experimental datasets available for validation are even scarcer than in frontal impact.

For pelvic response, two sources of data are available, which both have potentially significant limitations for human body model validation:

- Corridors scaled from the adult (Irwin et al., 2002). These include two setups for the pelvis: a drop test which loads the whole region and impactor test more focused on the greater trochanter. While these are used as reference for dummy design, the scaling is based on strong assumptions (e.g. use of scale factors in length, mass, moment of inertia and stiffness to characterize the 6 YO (years old) relative to the midsize adult male) which can be difficult to verify. For Irwin, the reference dimensions for the 6 YO are $1168 \mathrm{~mm}$ high for a weight of $20 \mathrm{~kg} 86$ which differs from the 6 YO baseline model $(1127 \mathrm{~mm}$, $23 \mathrm{~kg})$.

- PMHS (Post Mortem Human Surrogates) data: data from Ouyang were collected on PMHS, and do not rely on assumptions such as scaled curves. However, the Ouyang's PMHS differ significantly in terms of anthropometry from the model and also from Irwin. For example the two PMHS close to 6 YO are 1090 (1080) $\mathrm{mm}$ high for a weight of $20(16.5) \mathrm{kg}$.

(Kim et al., 2009) developed a finite element of a 10 YO child pelvis and used the Ouyang's results from four PMHS (mean age $9.4 \mathrm{YO}$ ) to identify material properties. This optimization-based approach is performed on an isolated pelvis and doesn't take in consideration the effects of the mass and soft tissues.

The objective of the study is to investigate the effect of anthropometry scaling on the response of a human body model and see if a same model may approximate the response from both sources. This could help understanding, through a model, the compatibility of Ouyang's PMHS results and Irwin's scaled corridors. For the current study, the response of the PIPER child model is compared to both references, before and after morphing the model to the anthropometry of the reference. 


\section{Methods}

\section{PIPER Scalable Child HBM}

The PIPER Scalable Child HBM is a finite element model developed in the Ls-Dyna explicit FE code (LSTC, Livermore, $\mathrm{CA}$ ) that aims to describe children of various ages. The baseline model describes a 6 YO child whose main anthropometric dimensions were normalized by nonlinear scaling (kriging interpolation) to the dimensions of a 6 YO as predicted by the GEBOD regressions (Cheng et al., 1994). This baseline has a standing height of $1127 \mathrm{~mm}$ with a total mass of $23 \mathrm{~kg}$. Its performance was checked against over 20 setups, mostly derived from PMHS tests, from regional (e.g. isolated head drop) to full body (e.g. sled), in frontal or side impact.

The model is comprised of approximately 546,000 elements of which 52,000 are rigid. They are distributed in 407 parts describing the main anatomical structures with material properties from the literature. With regards to the current application in side impact, the pelvis, proximal femur and ribcage are represented as deformable bones while the thoracolumbar spine is modelled using rigid vertebrae articulated using 6 degrees of freedom (d.o.f) beams. Internal organs of the thorax and abdomen are also described. Growth cartilage is described on the pelvis and proximal femur. Considering the aims of this study, the mechanical properties related to the pelvis were checked against literature sources. For a six year old, the cartilage can be considered as hyaline cartilage (Ponseti, 1978; Grissom et al., 2018) and the equivalent Young's modulus of $29 \mathrm{MPa}$ seemed appropriate testing literature results (Yamada (1970); Oloyede et al., 1992; Ruan et al., 2013). Special attention was given to the elastic modulus and Young's ratio for the pelvis trabecular bone as their values (11.35 GPa and 0.3) seemed overestimated in the PIPER model: they were replaced by $60 \mathrm{MPa}$ and 0.2 , respectively (between the values used by (Kim et al., 2009; Dalstra et al., 1995) for the elastic modulus). An elastic law was used and failure was not considered in the current study. The mechanical properties of the pelvis are summarized in Appendix 1 (Ruan et al, 2013; Shi et al, 2015; Kim et al,2009; Majumder et al, 2004; Dalstra et al, 1995; Parfitt et al, 2000; Meyer et al., 2011). Other body regions are also present in all simulations. They include the head (with deformable skull and brain), neck (with deformable vertebrae, discs, ligaments, muscles) and the extremities (with all joints modelled using 6 d.o.f. beams between rigid bones except the shoulder and the hip which are deformable). Superficial muscles and subcutaneous fat all around the model are modelled using a solid mesh that is covered by a shell representing the skin. Their properties are also provided in Appendix.

All simulations were run using the R7.1.3 of Ls-Dyna, with a time step of $0.32 \mu$ s obtained with marginal mass scaling (15 grams added).

\section{Side pelvic impact setups}

The Irwin's lateral drop tests setup consisted in a free fall of the model from heights of 0.5 and $1 \mathrm{~m}$ onto rigid impact surfaces (Figure 1a). Sacrum acceleration was saved as output of the simulation. (Irwin et al., 2002) proposed also corridors for drop heights of 2.0 and $3.0 \mathrm{~m}$. However the corresponding setups were not simulated in the present study because the characteristics of the padded surfaces were unknown.

The setup of the Irwin's pendulum pelvis lateral impacts was described in the ISO-TR9790 (1999). It consisted in impacting the greater trochanter region by applying to the pendulum an initial velocity varying between 4.5 and $11.5 \mathrm{~m} / \mathrm{s}$, as illustrated in Figure 1b. The impactor was scaled by (Irwin et al., 2002) from the $17.3 \mathrm{~kg}$ rigid impactor used for the midsize adult, resulting in a $3.89 \mathrm{~kg}$ pendulum for the $6 \mathrm{YO}$ dummy (used in the current study). Contact force calculated between pelvis and impactor was saved.

The Ouyang's setup consisted in delivering the impact on the pelvis using an impactor with a flat surface covered with Sorbothane ${ }^{\circledR}$ while the opposing side is against a fixed support covered with neoprene foam, as described in (Ouyang et al., 2003). The Ls-Dyna *MAT_VISCOELASTIC law was used to represent their behavior with material parameters from the literature (Al-Rumaih, 2009; Jeong et al., 2000; Sharma, 2002; Sorbothane, 2018, see Appendix 2). The loading conditions were simulated by applying the initial velocity to the impactor of the same mass $(3.24 \mathrm{~kg}$ ) as the one used in the tests (Figure 1c). Small variations of the orientation of the support and impactor (less than 10 degrees) were also simulated to evaluate if they have an effect in the response of the model. As the velocity varied between PMHS, the exact value was used for the comparisons 
between baseline and scaled models (see below). Impactor displacement and contact force between pelvis and impactor were saved as outputs of the simulations.

Anthropometric scaling using the PIPER software

The baseline model was scaled using the PIPER tool to match the stature and weight of the 6 YO anthropometry selected by Irwin et al. (that was used for the 6YO dummy) and of five PMHS ( 3 and 6 YO children in the Ouyang's setup). All scaling was performed within the PIPER software (v1.0.0, Open Source software available at www.piper-project.org).

In the PIPER software, scaling tools are based on Kriging interpolation (Jolivet et al., 2015). Targets are defined from anthropometric dimensions which are represented by a network of selected control points which are then used to morph the model. Several options are available in PIPER to compute the anthropometric dimensions and corresponding control points and transform the model. They were used for the current study in a three steps approach.

First, the baseline 3 YO model was generated using the PIPER Child scaling module. In that module, child models with external dimensions close to GEBOD (Cheng et al., 1994) can be generated based on a set of control points provided with the PIPER model and Kriging interpolation. Many of these points are on the skin in locations that allow associating them with anthropometric measurements defined in GEBOD. The position of these points is then updated depending on the target age using regressions from GEBOD and used for Kriging (see Appendix 5 for more details). The resulting models, called baseline 6 YO and 3 YO, were used for subsequent scaling for children of similar ages.

Then, the stature and weight of each PMHS were used to predict other anthropometric dimensions using regressions derived from the Snyder database (Snyder et al., 1977) in the anthropometric module. A corresponding network of control points defined using a simplified scalable model (provided with the PIPER software) was then used to represent these anthropometric dimensions on the model and both skeleton and skin were scaled together in the Kriging module.

Finally, the weight was adjusted - typically reduced - by adjusting the external circumferences in regions with large flesh thickness (e.g. legs, arms) using the simplified scalable model. The transformation was performed with the resulting skin envelope and fixed bones in the Kriging module.

The illustration in Figure 2 shows sections and segments dimensions with control points defined in the "Scaling Constraints" PIPER module to reduce the weight of the model

\section{Quantitative comparisons of simulations with experimental results}

Curves comparison between the Ouyang's tests and simulations was quantified using two approaches. For the first approach, although it is typically used for time histories, the CORAplus (CORrelation and Analysis) software CORA (2014) was applied to the force displacement signals (as the time histories are not available for the tests). Only the part of the signal with increasing displacement was kept. The ISO 18571 standard ISO/TS 18571 (2014) cross-correlation method was used to generate three subratings for phase, magnitude and slope. A second approach consisted in computing directly the peak values, displacement at peak force, initial slope until the peak force and area under the curve.

\section{Results}

\section{Scaling}

The models scaled to the Irwin's 6 YO stature and weight and the five Ouyang's PMHS are shown in Figure 3, with heights and weights summarized in Table 1. Segment masses for the Irwin scaled model and Irwin's 6 YO are compared in Appendix 3. [The models will be made available on the web]. 
Acceleration of the sacrum resulting from the free fall simulations for heights of 0.5 and $1 \mathrm{~m}$ are shown in Figure 4 for the baseline and the Irwin's scaled child models. The response of the model is within Irwin's acceleration limits for the scaled model and below the lower limit for the baseline.

Figure 5 represents the pendulum pelvis force vs the impactor velocity for the baseline and Irwin's scaled models compared to the Irwin's force corridor. The forces are inside the corridor for the $4.5 \mathrm{~m} / \mathrm{s} \mathrm{impact} \mathrm{and} \mathrm{above} \mathrm{for} \mathrm{all}$ other velocities. The difference between the baseline and scaled models was small (less than $0.26 \mathrm{kN}$ at 11.5 $\mathrm{m} / \mathrm{s}$ ). For comparison the result of the experimental testing performed by Yaek (2017) with the lateral impact child dummy prototype Q6s is also plotted in Figure 5 for an impact velocity of $6 \mathrm{~m} / \mathrm{s}$.

\section{Response in Ouyang's setup}

The impactor engaged the pelvic region, resulting in a compression of the soft tissues, followed by a pelvic translation, some spine lateral flexion, and a compression of the soft tissues on the fixed side.

For both experiments and simulations, the force increases almost linearly with the impactor displacement until reaching its peak. Then, the force decreases while the impactor displacement continues to increase (Figure 6). However, in the simulations, the peak force occurred at a larger displacement than in the tests, and the maximum impactor displacement was too small.

The simulations performed with the scaled models reduced the discrepancies observed between the baseline model and the experiment. The scaling improved the peak forces in the three cases with the highest discrepancies (PMHS 5, 8, 9), and improved the displacement at the peak force in all cases. Regarding the Phase, Magnitude and Slope computed with CORA, it was found that morphing improved the magnitude and slope for all five subjects, and phase for 4 of the 5 subjects (or an improvement for 14 out of 15 measures, detailed results in Appendix 6). Average improvements were $0.26,0.11,0.16$ for the Phase, Magnitude and Slope, respectively. These results were consistent with the direct calculation of peaks, slope and energy on the curves: morphing improved the peak force, displacement at peak force, slope and area under the curve by 5.7\%, 49.8\%, 20.7\% and $2.2 \%$, respectively. The scaling had limited effect on the peak displacement, which remained consistently smaller than the reported experimental results.

Figure 7 illustrates how small rotations (10 degrees or less) of the impactor and the support around the longitudinal axis may affect the shape of the curve for the subject 9: a rotation of the impactor (left) affects mainly the slope of the curve until the peak force while a rotation of the support (right) affects mainly the peak displacement. However the changes of impactor angle or support had more limited effect on the comparison metrics. Positive rotation angles of the impactor and support generally led to small improvements (increase of $0.111,0.015$ and 0.017 for phase, magnitude and slope, respectively) while negative angles degraded them slightly (decreasing of $0.33,0.03$ and 0.01 ).

Examples of Figure 8 show how small rotations of both impactor and support affect the response of the scaled model, in some cases bringing to closer to the experimental curves. However, the peak displacements remain too small compared to the experimental values.

\section{Discussion}

The performance of the PIPER child HBM in pelvis side impact was evaluated using three test setups derived from scaling adult or paediatric experimental data. With the anthropometric scaling based on regressions between dimensions, the mass of the scaled Child HBM were close to those of the PMHS used in the Ouyang's tests (within $0.9 \mathrm{~kg}$ ) and of the $6 \mathrm{YO}$ described in (Irwin et al., 2002) (difference of $0.34 \mathrm{~kg}$ ). Furthermore, for the scaling to the anthropometry of Irwin's 6 YO, the masses of the body segments were also approached. For example, the mass of the torso is $10.74 \mathrm{~kg}$ for the Irwin's 6 YO and $11 \mathrm{~kg}$ for the scaled model (Appendix 3). Two types of impactors were simulated: the pendulum impactor; which engages mainly the greater trochanter (Irwin et al., 2002) and the flat plate impactor, which engages both the iliac wing and the greater trochanter 
(Ouyang et al., 2003). The model captured most trends observed in the three setups, and model scaling helped reduce the discrepancies between test and simulation results in most cases. These results were confirmed using the CORA software as well as the calculation of peak force, slope, ... of the curves. Although the CORA methods are not designed to be used with force displacements data, the scores are coherent with the results of the other approach.In particular, model scaling helped bring the accelerations within the corridor defined for Irwin's drop tests. For a $1 \mathrm{~m}$ drop height, the pelvis acceleration is below the lower boundary of $91 \mathrm{~g}$ for the baseline model $(76.3 \mathrm{~g})$ and within the limits $91-111 \mathrm{~g}$ for the scaled model $(100.3 \mathrm{~g})$. This suggests that this setup is very sensitive to the anthropometry.

For the Ouyang's configuration, anthropometry and mass changes also improved the shape of the response curve and the timing of the peak when compared to the baseline model. Peak forces were also improved but the effect on the peak displacement very limited. As the PMHS weights were low considering their age, this suggests scaling accounting for the weight should be considered to develop response corridors. Regarding the peak displacements, it is worthwhile to note that, in the Ouyang's tests, the initial kinetic energy of the impactor is lower than the area under the force vs. displacement curve, by up to 28\% for the PMHS 8 (see Appendix 4). This may suggest either (1) a measurement issue or (2) an issue with the pneumatic device that was not completely decoupled after contact and that continued to transfer some energy to the impactor during the compression. However, this seems difficult to assess based on the information available in the Ouyang's publication.

To the contrary of Ouyang's plate impact and Irwin's drop test setups, the subject mass had limited effect in the simulation of Irwin's pendulum impact: at $11.5 \mathrm{~m} / \mathrm{s}$, the maximal value of the impactor force is $5.72 \mathrm{kN}$ for the baseline model and $5.46 \mathrm{kN}$ for the scaled model. While the reason is not certain, it can be observed that for that setup, the load is applied locally to the greater trochanter area and transmitted to the acetabulum through the femoral head while the loading was more distributed for the other setups. Overall, while the response of the HBM at $4.5 \mathrm{~m} / \mathrm{s}$ is within the Irwin's corridor, it is above for higher velocities but closer to the corridor than the Q6s dummy (Figure 5). The difference between the model response and the corridor increases with the velocity. Based on Irwin et al. (2002), the 6 YO corridor has slopes of 0.24 and $0.30 \mathrm{kN} /\left(\mathrm{m} \cdot \mathrm{s}^{-1}\right)$ for the lower and upper boundaries, respectively. In the simulation, the force also increases with the velocity but with a higher slope of $0.41 \mathrm{kN} /\left(\mathrm{m} \cdot \mathrm{s}^{-1}\right)$ (obtained by linear regression). The reasons for this mismatch are not clear and could be coming from the model itself or from the simplified scaling assumptions. Irwin's slopes are scaled from the midsize adult male corridor (slopes of 0.74 and $0.91 \mathrm{kN} /\left(\mathrm{m}_{\mathrm{s}} \mathrm{s}^{-1}\right)$ ) defined in ISO-TR9790, (1999) using a force scale factor $\mathrm{R}_{\mathrm{F}}$ (defined by Mertz (1984)). That factor depends on the masses of the impacted body segments (taken here as the whole lower torso and the lower extremities), the impactors masses, the bone moduli (based on parietal bone) and the erect sitting heights, all estimated on the $6 \mathrm{YO}$ and the adult. The scaling does not account for local parameters such as the width of the pelvis, the cartilage or the bone thickness. The various assumptions should be investigated in the future.

To expand on the comparison between curve scaling and model morphing approaches, it would have been interesting to scale the response curves from Ouyang to account for the anthropometric differences. However, this is not straightforward as the setup is not a simple pendulum loading since the pelvis excursion is limited by a support plate. A simple pendulum scaling approach would have a marginal effect on the response curve (example in Appendix 7-figure $\mathrm{H}$ ) but its validity is questionable beyond the beginning of the loading when significant loads are carried by the support plate, (i.e. $2.97 \mathrm{kN}$ for the subject 8 ). A more adequate scaling methodology could be further investigated.

Regarding the Irwin setups, scaling the model response using Irwin coefficients had a marginal effect for both lateral drop and pendulum, while model morphing had much larger effect for the lateral drop (figure $\mathrm{F}$ and figure $\mathrm{G}$ in Appendix 7).

\section{Scaling Limitations}

In Ouyang's study, the relative width of the PMHS at the greater trochanter and pelvic wings were not provided. More or less prominent iliac wings or greater trochanters may lead to different loading paths when impacted by a plate. This was documented for the adult by (Lebarbé et al., 2016). Rotations of up to 10 degrees about X in 
different directions were applied to the impactor and support to simulate a difference of loading path. This led to curve shape changes and, in some cases, it reduced the difference between simulation and experiment (e.g. PMHS 4 and 8, Figure 8).

More generally, due to the absence of detailed anthropometry of the PMHS, predictions had to be made using average external dimensions derived from the Snyder database. This is an important limitation of the scaling as it does not account for the PMHS specificities, as for example changes of soft tissues thickness or skeletal dimension. With the objective to improve scaling, it would be interesting if such geometrical parameters could be considered for future work, either through subject specific modelling or through the use of statistical models for the skeleton.

Another limitation concerns the PIPER software framework where the scaling is performed only on the anthropometry of the model without considering variations of the material properties with the age.

\section{Conclusion}

In order to study its response in side impact, the PIPER child model was scaled to approach the size of the PMHS used in Ouyang's study or reference dimensions for the 6 YO as specified by Irwin using the PIPER software framework. The response of the scaled models demonstrates an effect of the anthropometry on the side impact response. The effect may explain some of the discrepancies when comparing the baseline child model with the Ouyang and Irwin's responses, and does not support specific modifications of the baseline model.

Discrepancies remain mainly on the effect of impact velocity in Irwin's pendulum lateral pelvic impact. While the model is within the corridor at $4.5 \mathrm{~m} / \mathrm{s}$, it is above for higher velocities, although closer to the corridor than the Q6s. The reasons for this mismatch should be further investigated.

\section{Acknowledgements}

This research has received funding from the European Union Seventh Framework Program ([FP7/2007-2013]) under grant agreement $n^{\circ} 605544$ [PIPER project]). The PIPER child model was released with contributions of UCBL-Ifsttar, KTH and TU Berlin. The PIPER child model, PIPER software and VFSB CRS model can be 


\section{Reference}

Al-Rumaih, W.S., 2009. A novel tuned visco-elastic damper for floor vibration abatement (PhD in Mechanical Engineering). University of Dayton, Dayton, Ohio - USA.

Beillas, P., Giordano, C., Alvarez, V., Li, X., Ying, X., Chevalier, M.-C., Kirscht, S., Kleiven, S., 2016. Development and performance of the PIPER scalable child human body models. In Proceedings of the 14th International Conference Protection of Children in Cars, Munich.

Beillas, P., Soni A., Chevalier M-C., Johannsen H., Müller G.,, Holtz J., 2014. Q6 Dummy Thoracic Response and Diagonal Belt Interactions: Observations based on Dummy Testing and Human and Dummy Simulations. In the Proceedings of the IRCOBI Conference, Berlin.

Cheng, H., Obergefell, L., Rizer, A., 1994. Generator of Body Data (GEBOD) manual (No. Report AL/CF-TR1994-0051). Human effectiveness Directorate, Crew Survivability and Logistics Division, Write-Patterson Air Force Base, Ohio.

CORA, 2014. CORrelation and Analysis Software, CORA plus v4.04. PDB, Partnership for Dummy technology and Biomechanics. URL http://www.pdb-org.com/en/information/18-cora-download.html (accessed 2.21.20).

Dalstra, M., Huiskes, R., van Erning, L., 1995. Development and validation of a three-dimensional finite element model of the pelvic bone. J. Biomech. Eng. 117, 272-278.

Giordano, C., Li, X., Kleiven, S., 2017. Performances of the PIPER scalable child human body model in accident reconstruction. PLOS ONE 12, e0187916. https://doi.org/10.1371/journal.pone.0187916

Grissom, L.E., Harty, M.P., Guo, G.W., Kecskemethy, H.H., 2018. Maturation of pelvic ossification centers on computed tomography in normal children. Pediatr. Radiol. 48, 1902-1914. https://doi.org/10.1007/s00247-0184233-6

Irwin, A.L., Mertz, H.J., Elhagediab, A.M., Moss, S., 2002. Guidelines for assessing the biofidelity of side impact dummies of various sizes and ages. Stapp Car Crash J. 46, 297-319.

ISO-TR9790, 1999. Road vehicles - Anthropomorphic side impact dummy - Lateral impact response requirements to assess the biofidelity of the dummy (Technical Report No. Reference number ISO/TR 9790:1999(E)).

ISO/TS 18571, 2014. Road vehicles — Objective rating metric for non-ambiguous signals.

Jeong, D.Y., Kwok,P., Canha, J.V., 2000. Characterization of Deformable Materials in the THOR Dummy, in: 28th International Workshop. Presented at the Injury Science Research, Atlanta, Georgia, pp. 147-157.

Jolivet, E., Lafon, Y., Petit, P., Beillas, P., 2015. Comparison of Kriging and Moving Least Square Methods to Change the Geometry of Human Body Models. Stapp Car Crash J. 59, 337-357.

Kim, J., Li, Z., Ito, Y., Huber, C., Shih, A., Eberhardt, A., Yang, K., King, A., Soni, B., 2009. Finite element model development of a child pelvis with optimization-based material identification. J Biomech 42 2191-2195.

Lebarbé, M., Baudrit, P., Potier, P., Petit, P., Trosseille, X., Compigne, S., Masuda, M., Fujii, T., Douard, R., 2016. Investigation of Pelvic Injuries on Eighteen Post Mortem Human Subjects Submitted to Oblique Lateral Impacts. 60th Stapp Car Crash Conf. 60, 89-134.

Majumder, S., Roychowdhury, A., Pal, S., 2004. Dynamic response of the pelvis under side impact load - a three-dimensional finite element approach. Int. J. Crashworthiness 9, 89-103. https://doi.org/10.1533/ijcr.2004.0274

Mertz, H.J., 1984. A Procedure for Normalizing Impact Response Data. SAE Trans. 93, 351-358. 
Meyer, F., Deck, C., Beillas, P., Behr, M., Eisenach, A., Yang, J., 2011. Report on child numerical and experimental injury criteria, CASPER Project Deliverable D2.5

Oloyede, A., Flachsmann, R., Broom, N.D., 1992. The Dramatic Influence of Loading Velocity on the Compressive Response of Articular Cartilage. Connect. Tissue Res. 27, 211-224.

Ouyang, J., Zhu, Q., Zhao, W., Xu, Y., Chen, W., Zhong, S., 2003. Experimental cadaveric study of lateral impact of the pelvis in children. J. First Mil. Med. Univ. 23, 397-408.

Parfitt, A.M., Travers, R., Rauch, F., Glorieux, F.H., 2000. Structural and cellular changes during bone growth in healthy children. Bone 27, 487-494. https://doi.org/10.1016/S8756-3282(00)00353-7

Ponseti, I., 1978. Growth and development of the acetabulum in the normal child. Anatomical, histological, and roentgenographic studies. J. Bone Joint Surg. Am. 60, 575-585.

Ruan, J., Rouhana, S., Barbat, S., 2013. Development of a Six-Year Old Digital Human Body Model for Vehicle Safety Analysis, in: Proceedings of the FISITA 2012 World Automotive Congress, Lecture Notes in Electrical Engineering. Springer Berlin Heidelberg, pp. 207-222.

Sharma, A., Shukla, A., Prosser, R.A., 2002. Mechanical characterization of soft materials using high speed photography and split hopkinson pressure bar technique. J. Mater. Sci. 37, 1005-1017. https://doi.org/10.1023/A:1014308216966

Shi, D., Wang, F., Wang, D., Li, X., Wang, Q., 2014. 3-D finite element analysis of the influence of synovial condition in sacroiliac joint on the load transmission in human pelvic system. Med. Eng. Phys. 36, $745-753$. https://doi.org/10.1016/j.medengphy.2014.01.002

Snyder, R.G., Schneider, L.W., Owings, C.L., Reynolds, H.M., Golomb, D.H., Sckork, M.A., 1977. Anthropometry of Infants, Children, and Youths to Age 18 for Product Safety Design. Final Report (Final Report No. UM-HSRI-77-17 / SAE SP-450). Highway Safety Research Institute, The University of Michigan Ann Arbor, Michigan, USA.

Sorbothane, I., 2018. Material Properties of Sorbothane. URL http://www.sorbothane.com/Data/Sites/31/pdfs/data-sheets/101-sorbothane-material-properties.pdf (accessed 7.25.19).

Yaek, J., 2017. Biofidelity Assessment Of 6-Year-Old Anthropometric Test Devices (atds) And Scaling Laws In Lateral Impact (PhD Dissertation No. 1902). Wayne State University Dissertations, Detroit, Michigan.

Yamada, H., 1970. Strength of biological materials, The Williams \& Wilkins Company. ed. Evans FG, Baltimore. 


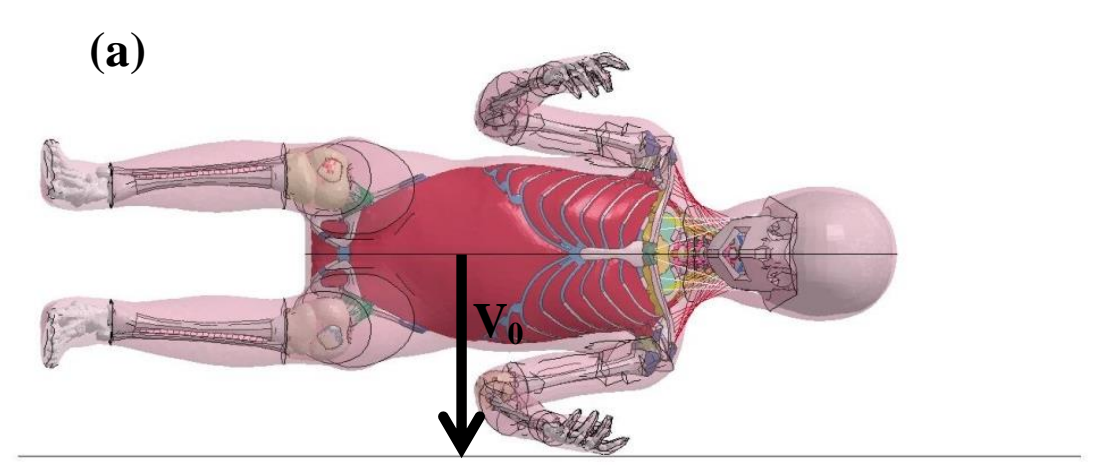

(b)

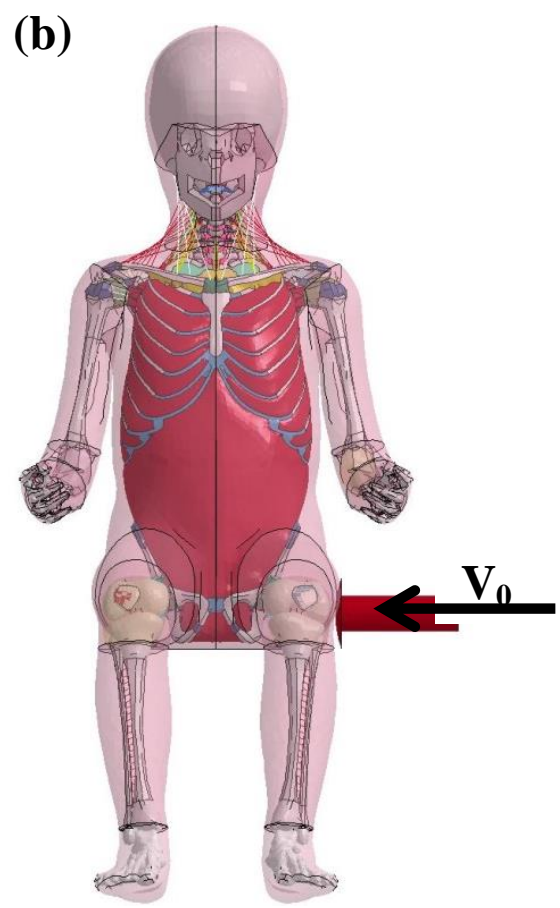

(c)

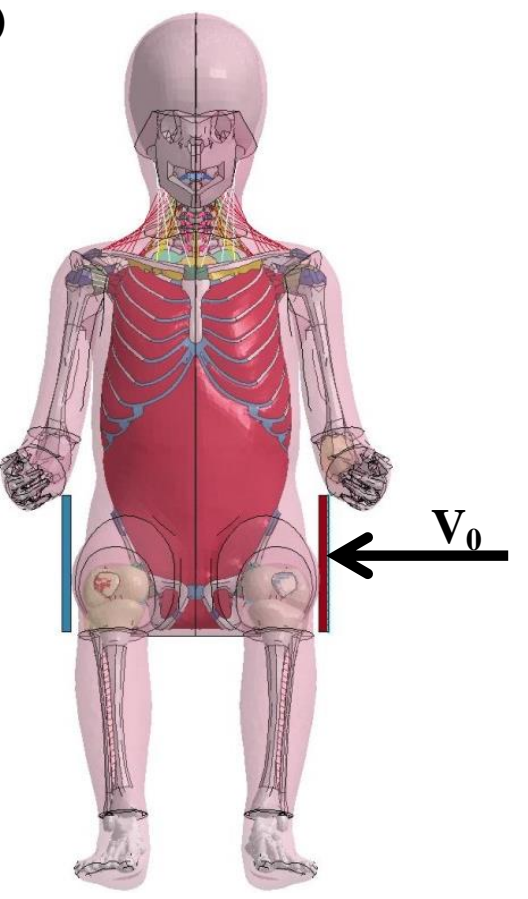

345

346

Figure 1: Pelvis lateral impact used to assess the performance of the PIPER Child HBM. (a) Irwin's drop test setup (b) Irwin's pendulum setup (c) Ouyang's setup with support (blue) and impactor (red) 


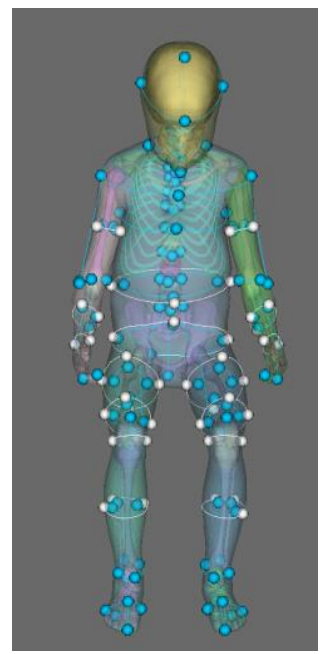

Figure 2: Source (white) and target (blue) sections and segments with control points defined in the PIPER

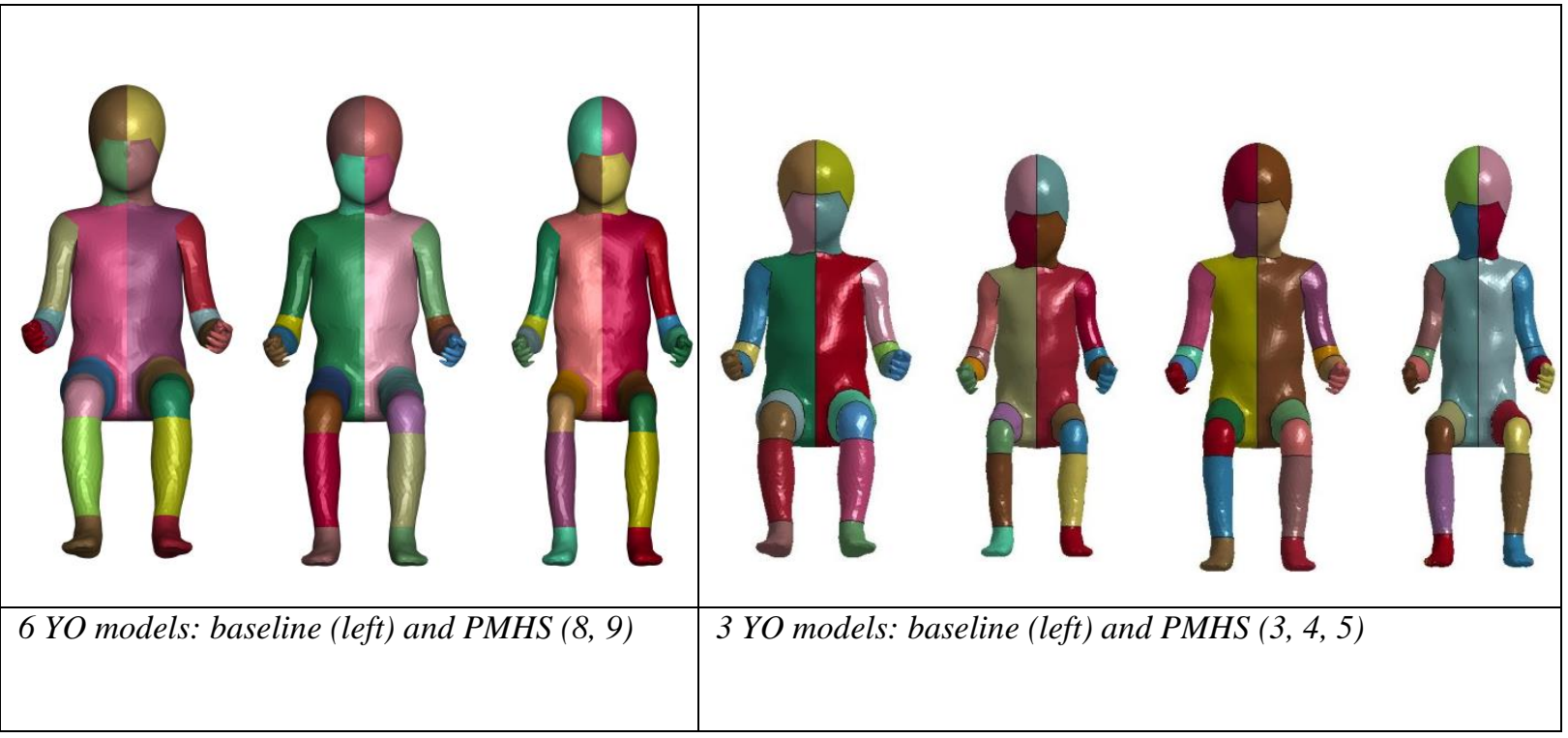

Figure 3: Scaling to Ouyang's PMHS anthropometry. See Table 1 for the characteristics 


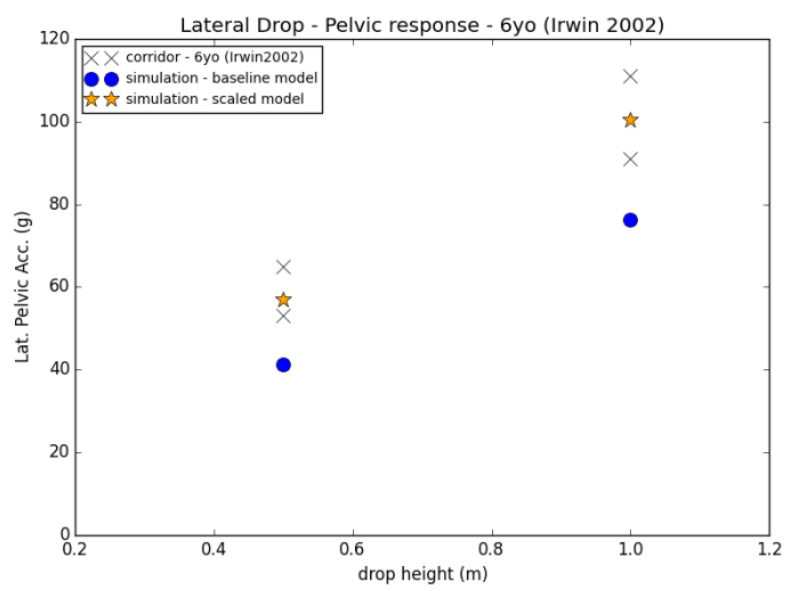

357 Figure 4: Sacrum acceleration vs drop height for the baseline (blue) and scaled (orange) models compared to the Irwin's corridor (Irwin et al., 2002). The PIPER baseline model was scaled to the Irwin's 6 YO stature and weight.

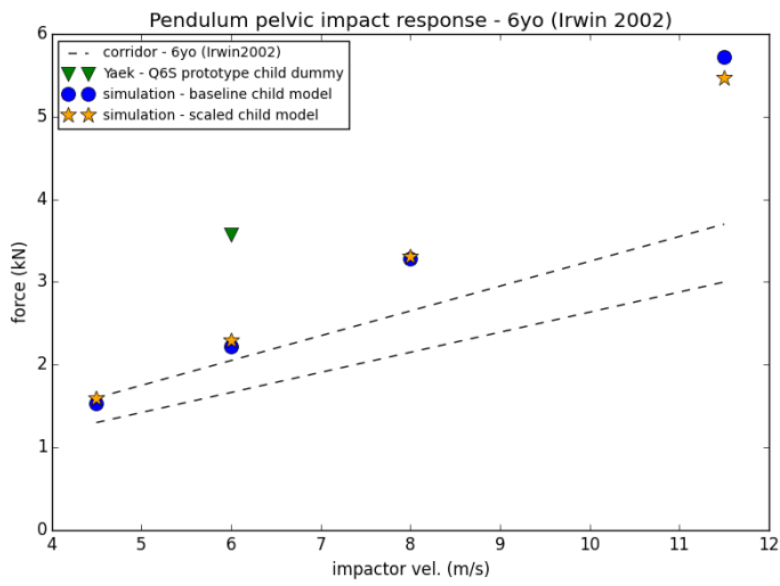

Figure 5: Pendulum pelvis force vs impactor velocity for the baseline (blue) and scaled (orange) models compared to the Irwin's corridor (Irwin et al., 2002) 

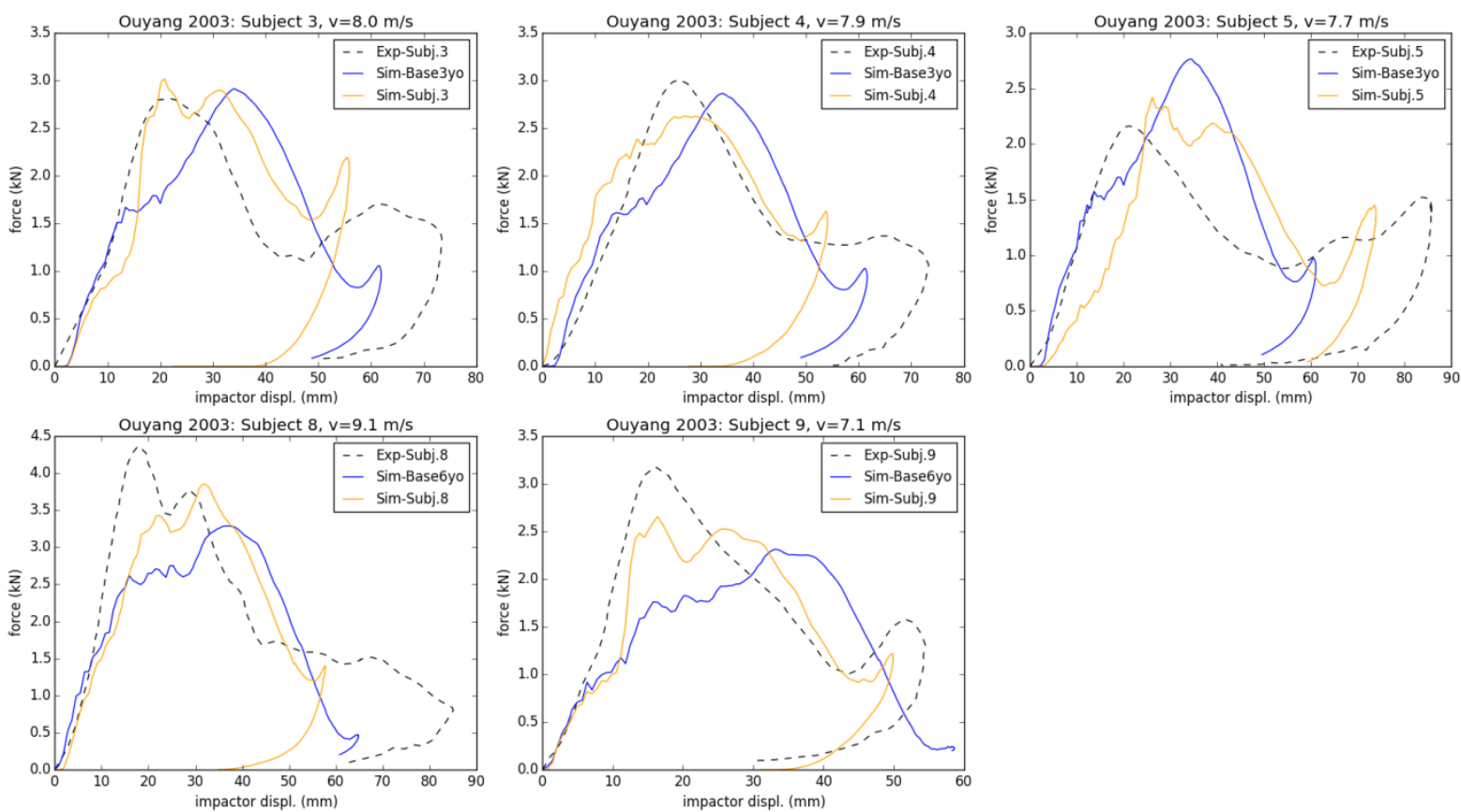

Figure 6: Response comparison between the baseline (blue), scaled (orange) and test PMHS (dashed) for five PMHS tested in (Ouyang et al., 2003). The 3 YO model is used as the baseline for the first three PMHS (top) and the 6 YO is used for the last two (bottom)
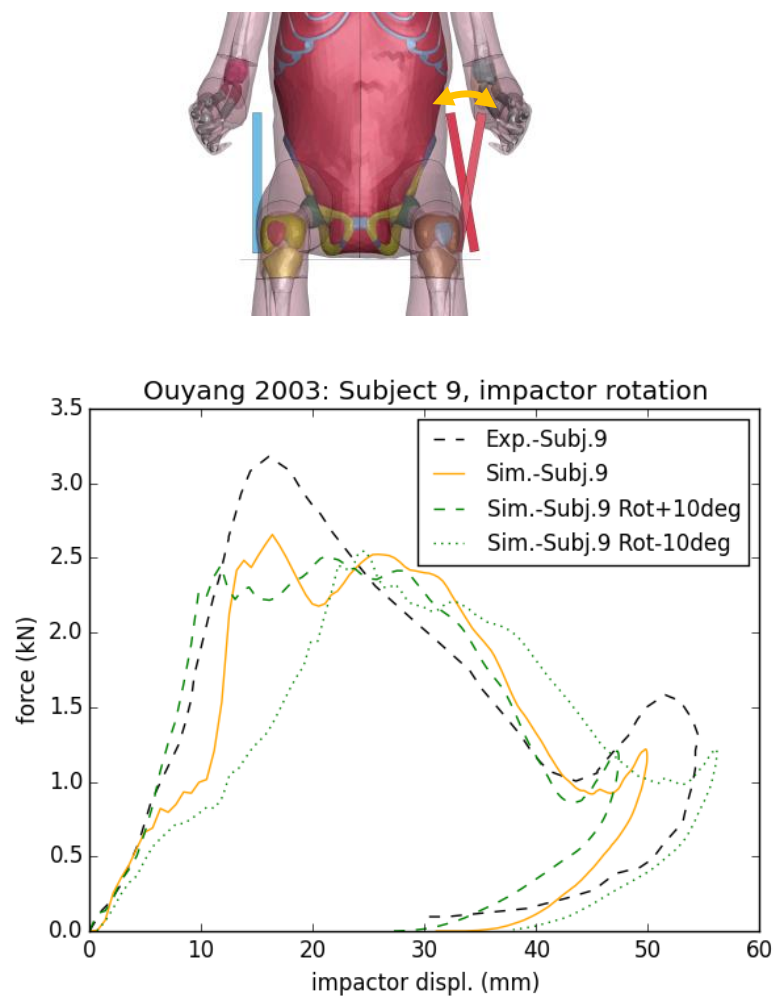
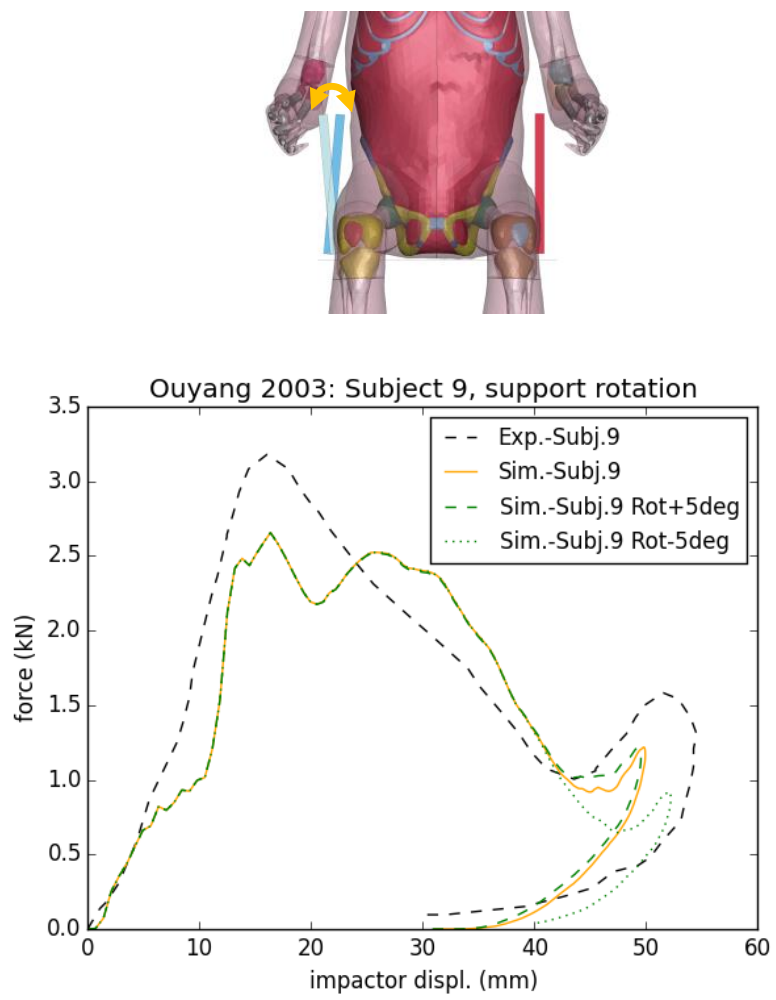

Figure 7: Response of the model scaled to the PMHS 9 impacted with small variations in the orientation of the impactor (left) or support (right). The initial configuration curve (orange), is compared to the modified impactor conditions (green) and the test (black). 


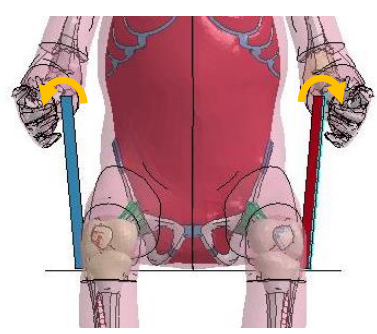

Ouyang 2003: Subject 4, impactor and support rotation

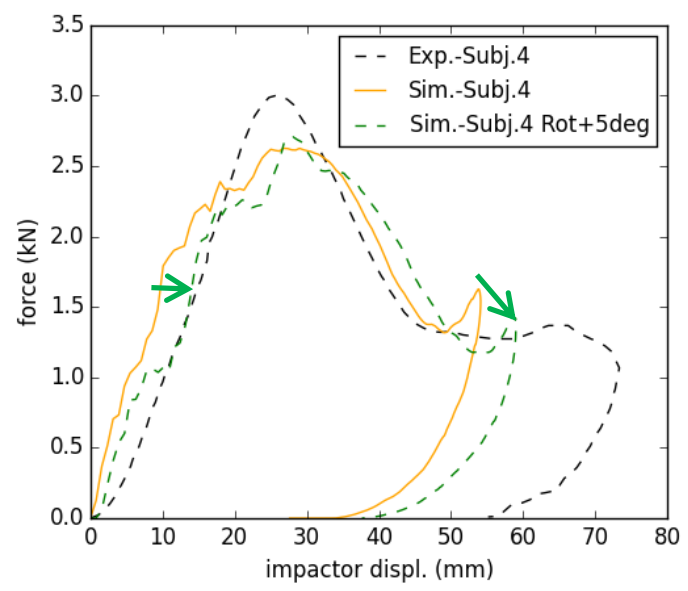

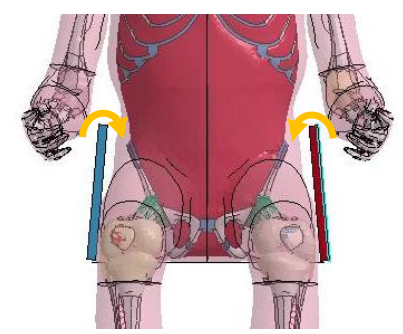

Ouyang 2003: Subject 8, impactor and support rotation

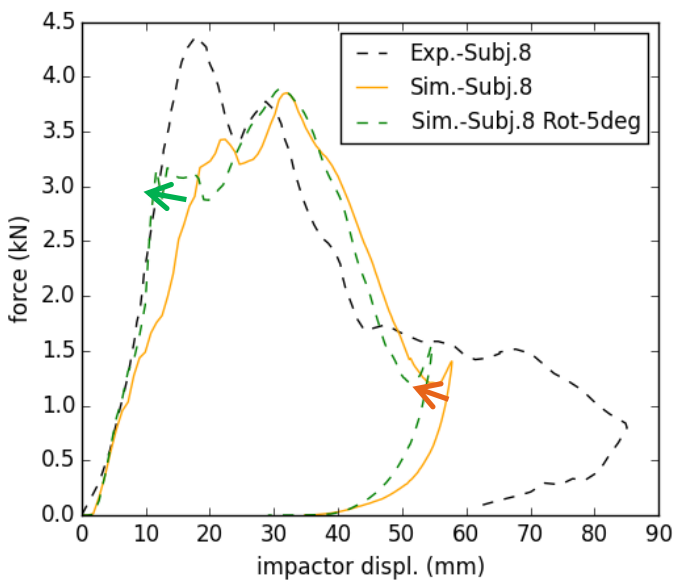

Figure 8: Response of the model scaled to the PMHS 4 (left) and PMHS 8 (right) impacted with small variations in the orientation of the impactor and support. The initial configuration curve (orange) is compared to the modified impactor and support conditions (green) and the test (black).

Table 1: Summary of statures and masses for the PMHS and corresponding scaled models

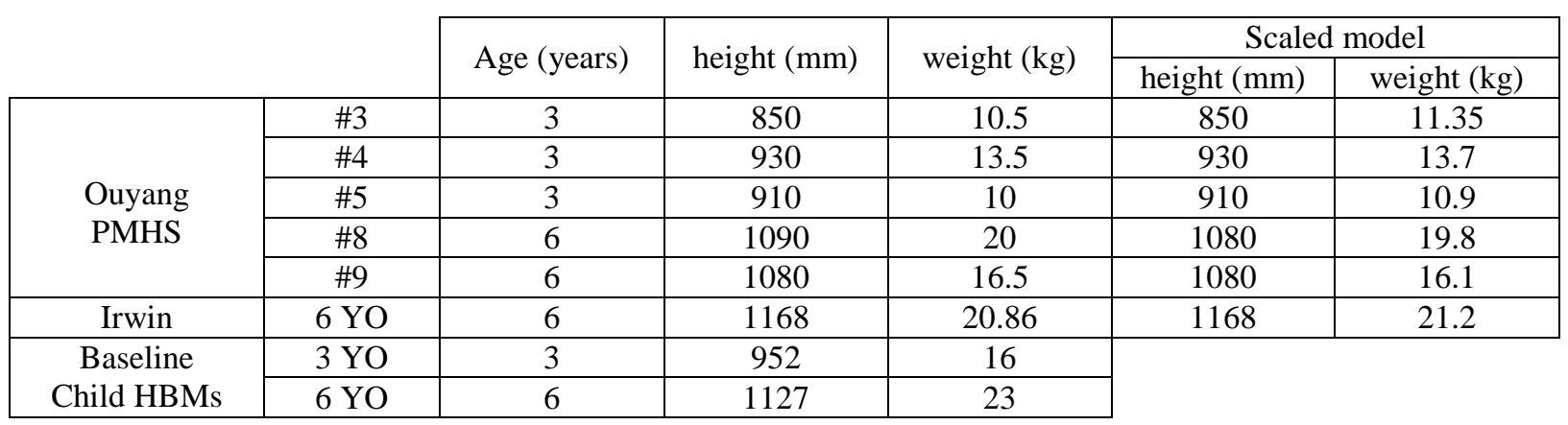




\section{Mechanical properties for the pelvis of the PIPER child HBM}

The pelvis is meshed with deformable elements describing the cancellous and cortical bone (tetrahedral and shell elements), as well as the growth cartilage based on the CT scans (Erreur ! Source du renvoi introuvable.). Mechanical properties are summarized in Erreur ! Source du renvoi introuvable.

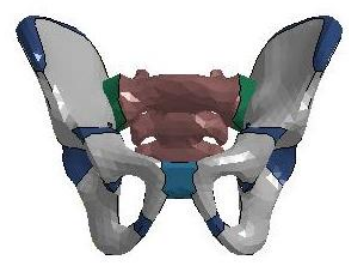

Figure I : Pelvis modeling with bones in grey, joint in green and growth cartilage in blue

Table B : Summary of the pelvis properties for the PIPER child HBM. Source of the original properties: EC funded CASPER project - deliverable D2.5 (Meyer et al., 2011). References are only provided for comparison purpose. As large differences were observed for the trabecular bone, its properties were changed and the original value was provided in footnote.

\begin{tabular}{|c|c|c|c|}
\hline Tissue & Material & $\begin{array}{l}\text { Young E, Bulk K, Shear } \\
\text { G modulus [GPa], Decay } \\
\text { constant } \beta\left[\mathrm{ms}^{-1}\right] \text {, Poisson } \\
v \text {, shell thickness e[mm] }\end{array}$ & References \\
\hline Pelvic cartilage & $\begin{array}{l}\text { Visco- } \\
\text { elastic }\end{array}$ & $\begin{array}{l}\mathrm{K}=0.083, \mathrm{G}_{0}=0.01, \\
\mathrm{G}_{\mathrm{i}}=0.0025, \beta=0.25\end{array}$ & $\begin{array}{l}\text { (Ruan et al., 2013): } \\
\mathrm{K}=0.053, \mathrm{G}_{0}=0.009, \mathrm{G}_{\mathrm{i}}=0.096, \beta=0.0015 \\
\text { Corresponding modulus } \mathrm{E}=0.029 \text {, between } \\
\text { values from (Oloyede et al., 1992): } \mathrm{E}=0.021 \text { and } \\
\text { (Yamada, 1970) : } \mathrm{E}=0.050\end{array}$ \\
\hline $\begin{array}{l}\text { Pubic symphysis } \\
\text { cartilage }\end{array}$ & $\begin{array}{l}\text { Visco- } \\
\text { elastic }\end{array}$ & $\begin{array}{l}\mathrm{K}=0.083, \mathrm{G}_{0}=0.01 \\
\mathrm{G}_{\mathrm{i}}=0.0025, \beta=0.25\end{array}$ & $\begin{array}{l}\text { (Ruan et al., 2013): } \\
\mathrm{K}=0.053, \mathrm{G}_{0}=0.009, \mathrm{G}_{\mathrm{i}}=0.096, \beta=0.0015 \\
\text { Corresponding modulus } \mathrm{E}=0.029: \text { between } \\
\text { values from (Oloyede et al., 1992): } \mathrm{E}=0.021 \text { and } \\
\text { (Yamada, 1970) : } \mathrm{E}=0.050\end{array}$ \\
\hline $\begin{array}{l}\text { Sacro-Iliac joint } \\
\text { cartilage }\end{array}$ & Elastic & $\mathrm{E}=0.1, v=0.3$ & (Shi et al., 2014) : $E=0.054, v=0.4$ \\
\hline $\begin{array}{l}\text { Pelvis trabecular } \\
\text { bones (3D) }\end{array}$ & Elastic $^{1}$ & $\mathrm{E}=0.06^{2}, v=0.2^{3}$ & $\begin{array}{l}\text { E between values from (Kim et al., 2009) : } 0.0448 \\
\text { and (Majumder et al., 2004), (Dalstra et al., } \\
\text { 1995): } 0.070\end{array}$ \\
\hline $\begin{array}{l}\text { Pelvis cortical } \\
\text { bones (2D) }\end{array}$ & Elastic & $\mathrm{E}=15, \mathrm{v}=0.3, \mathrm{e}=1$ & $\begin{array}{l}\text { E between values from (Kim et al., 2009) : } 11.6 \\
\text { and (Dalstra et al., 1995): } 17 \\
\text { (Parfitt et al., 2000) : e=0.8 }\end{array}$ \\
\hline
\end{tabular}

\footnotetext{
${ }^{1}$ Instead of an elastoplastic material as defined in the PIPER Child HBM

${ }^{2}$ Instead of the value of $11.35 \mathrm{GPa}$ defined in the PIPER Child HBM

${ }^{3}$ Instead of the value of 0.29 defined in the PIPER Child HBM
} 
Mechanical properties for the sorbothane impactor and neoprene support

405

406

407

408

409

410

411

412

413

Sorbothane and neoprene are modelled as viscoelastic materials with the LS-Dyna *MAT_VISCOELASTIC law. Material properties are given in Table $\mathrm{C}$.

Table C: Parameters of the LS-Dyna *MAT_VISCOELASTIC law for sorbothane and neoprene

\begin{tabular}{|c|c|c|}
\hline & Sorbothane & Neoprene \\
\hline References & $\begin{array}{c}\text { (Sorbothane, 2018), } \\
\text { (Al-Rumaih, 2009) or } \\
\text { assumed }\end{array}$ & (Jeong et al., 2000) \\
\hline Density $\left(10^{-6} \mathrm{~kg} / \mathrm{mm}^{3}\right)$ & 1.3 & 1.23 \\
\hline Elastic Bulk modulus (GPa) & 4 & 0.0785 \\
\hline Short-time shear modulus (GPa) & $9 \mathrm{e}-04$ & $8.3 \mathrm{e}-03$ \\
\hline Long-time shear modulus (GPa) & $4 \mathrm{e}-04$ & $1.8 \mathrm{e}-03$ \\
\hline Decay constant $\left(\mathrm{ms}^{-1}\right)$ & 0.05 & 0.53 \\
\hline
\end{tabular}

An alternative source for sorbothane properties was also considered: the experimental engineering stress-strain curve published by (Sharma et al., 2002)(Figure J) was used as input the LS-Dyna *MAT_HILL_FOAM law. The effect on the response was marginal (Figure $\mathrm{K}$ ) and the viscoelastic properties were kept for the final simulations.

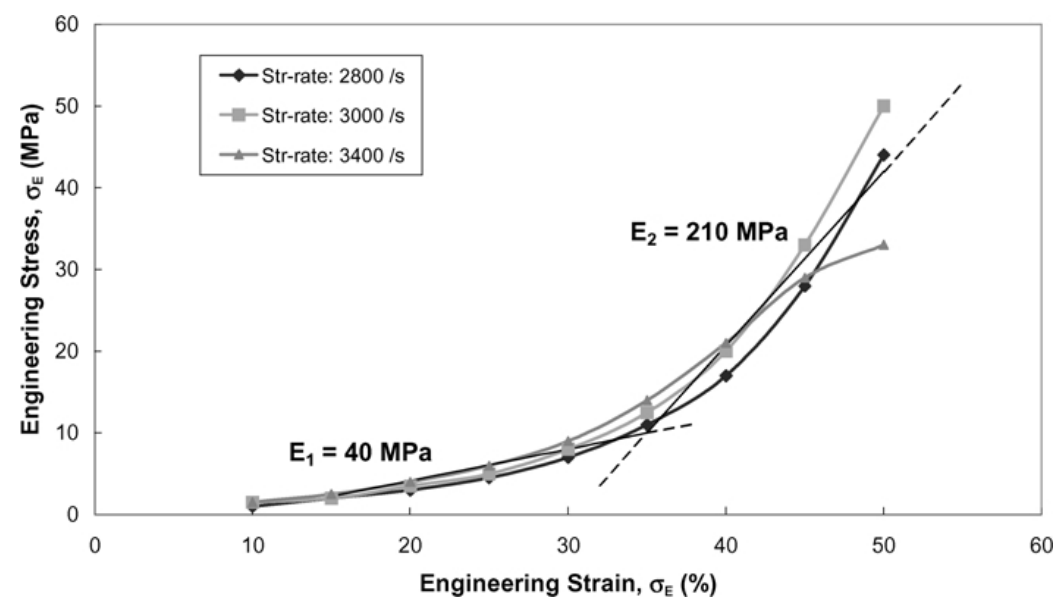

Figure J: Engineering stress-strain plot for sorbothane extracted from (Sharma et al., 2002) 


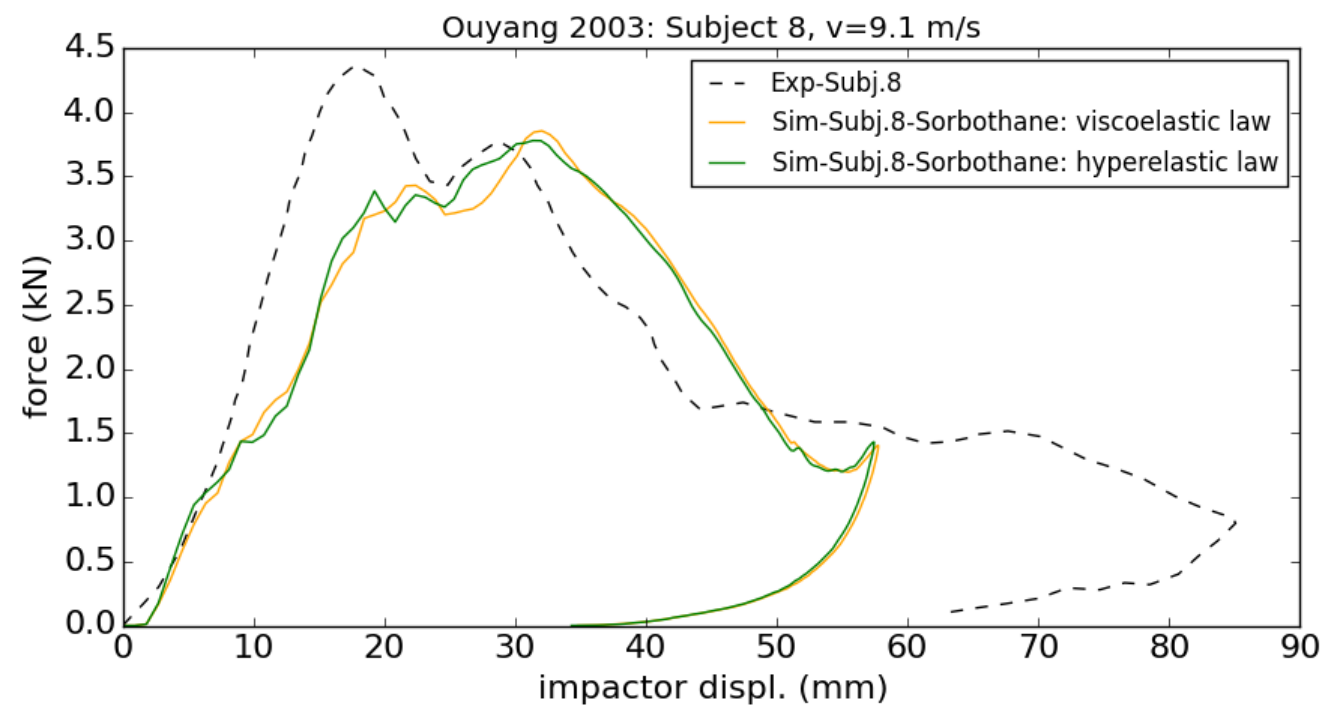

415

416 Figure K: Simulation of the response of the HBM (PMHS 8 of Ouyang) by modelling sorbothane covering the 417 impactor with $a * M A T \_V I S C O E L A S T I C$ or $a * M A T \_H I L L \_F O A M ~ l a w$. 
Appendix 3

420 Segment masses and total body mass for the PIPER HBM scaled to the Irwin's 6 YO stature and weight.

421 Table D: Segment masses and total body mass for the Irwin's 6 YO and the scaled model (units: $k g$ )

\begin{tabular}{|l|c|c|}
\hline Segment & Irwin's 6 YO & Scaled model \\
\hline Head + Neck & 3.97 & 3.82 \\
\hline Torso & 10.74 & 11 \\
\hline Upper Extremities & 1.87 & 2.1 \\
\hline Lower Extremities & 4.28 & 4.24 \\
\hline Total Body Mass & $\mathbf{2 0 . 8 6}$ & $\mathbf{2 1 . 1 6}$ \\
\hline
\end{tabular}

422 


\section{Appendix 4}

Ouyang's setup: comparison between the initial kinetic energy of the impactor and the work done by the contact force

For each Ouyang's PMHS, the work done by the contact force between the HBM and the impactor is evaluated from the integration of the curve force vs impactor displacement (Figure L).

\section{Contact Force}

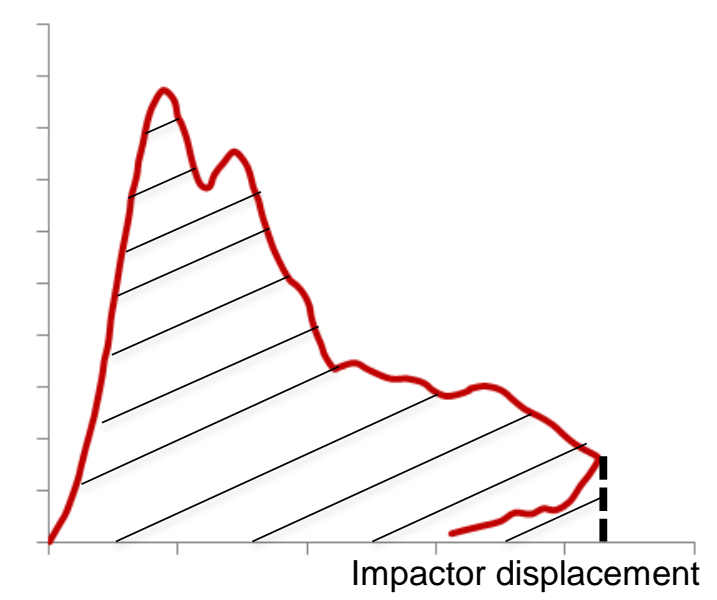

Figure L: Contact force vs impactor displacement to evaluate the work done by the force.

Table E: Comparison between the initial kinetic energy of the impactor and the work done by the HBM-impactor contact force (mass of the impactor $=3.24 \mathrm{~kg}$ )

\begin{tabular}{|c|c|c|c|c|c|c|}
\hline PMHS & Age & $\begin{array}{c}\text { Impact } \\
\text { velocity }\end{array}$ & $\begin{array}{c}\text { Impactor } \\
\text { kinetic } \\
\text { energy }\end{array}$ & $\begin{array}{c}\text { Work done } \\
\text { by the } \\
\text { contact } \\
\text { force } \\
\text { Joules }\end{array}$ & variation & variation \\
\hline 3 & years & $m / s$ & Joules & 120 & $\%$ \\
\hline 4 & 3 & 8 & 103.7 & 120 & 16.3 & $15 \%$ \\
\hline 5 & 3 & 7.7 & 101.1 & 115.5 & 14.4 & $13 \%$ \\
\hline 8 & 6 & 9.1 & 134.2 & 177 & 42.8 & $28 \%$ \\
\hline 9 & 6 & 7.1 & 81.7 & 94.2 & 12.5 & $14 \%$ \\
\hline
\end{tabular}




\section{Appendix 5}

\section{Scaling using the child scaling module}

This module is dedicated to the scaling of the PIPER scalable model as a function of the age or stature. A set of 291 control points (source points in orange) provided with the PIPER metadata are defined on the skin surface or on the near spine. The points on the skin are associated with anthropometric dimensions used in GEBOD (Cheng et al. 1994). Using regressions linking age (in this example the target age is 3 YO) to the anthropometric dimensions, the control point positions can be updated, generating target points (in blue). For the points near the spine, separate assumptions are used (e.g. linear scaling) in order to avoid creating local deformities. Model morphing (kriging) is then driven by the control points. In this example a preview of the scaled model (3YO) is shown in red.

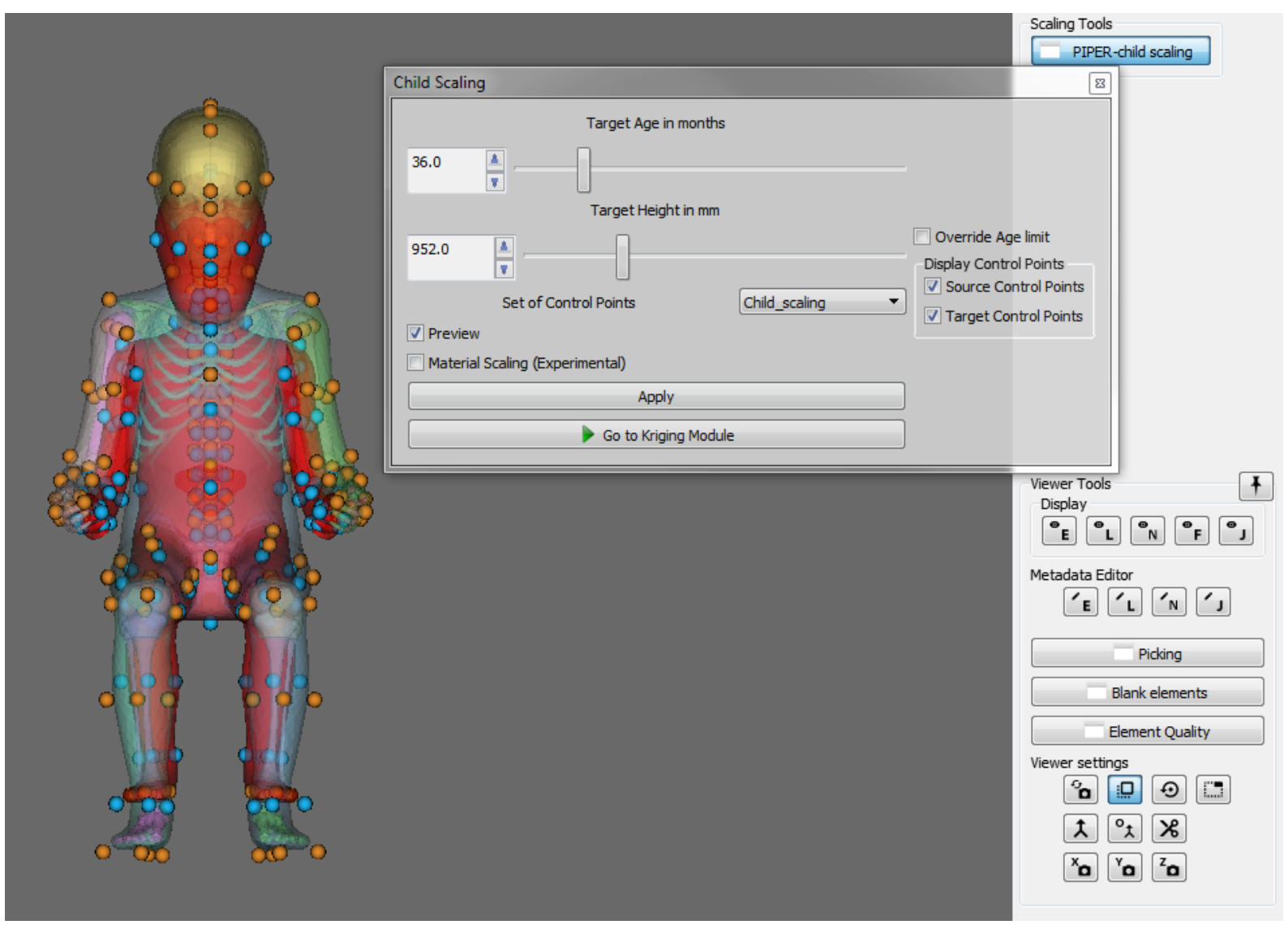

Figure M : scaling of the PIPER $6 Y O$ child model using the child scaling module 
Table F : Cora scores for the curves of figure 6

\section{Appendix 6}

Quantitative comparisons of simulations with experimental results

1. Quantitative comparisons using the CORA software

\begin{tabular}{|c|l|c|c|c|}
\hline $\begin{array}{c}\text { Ouyang } \\
\text { PMHS }\end{array}$ & Child model & Phase & Magnitude & Slope \\
\hline \multirow{2}{*}{$\# \mathbf{3}$} & Baseline & 0.1 & 0.813 & 0.724 \\
\cline { 2 - 5 }$\# \mathbf{\# 4}$ & Scaled Model & 0.6 & 0.845 & 0.843 \\
\cline { 2 - 5 } & Saseline & 0.5 & 0.873 & 0.684 \\
\hline \multirow{2}{*}{$\# \mathbf{5}$} & Baseline & 0.455 & 0.685 & 0.523 \\
\cline { 2 - 5 } & Scaled Model & 0.091 & 0.869 & 0.779 \\
\hline \multirow{2}{*}{$\# \mathbf{\# 9}$} & Baseline & 0.5 & 0.726 & 0.557 \\
\cline { 2 - 5 } & Scaled Model & 0.6 & 0.842 & 0.747 \\
\cline { 2 - 5 } & Baseline & 0.111 & 0.694 & 0.65 \\
\cline { 2 - 5 } & Scaled Model & 0.778 & 0.864 & 0.718 \\
\hline \multirow{2}{*}{$\begin{array}{l}\text { average } \\
\text { scaled Model/Baseline }\end{array}$} & improment & $\mathbf{0 . 2 6}$ & $\mathbf{0 . 1 1}$ & $\mathbf{0 . 1 6}$ \\
\hline
\end{tabular}

Table G : Cora scores for the curves of figure 7

\begin{tabular}{|l|l|c|c|c|}
\hline \multicolumn{1}{|c|}{ Scaled Model } & Phase & Magnitude & Slope \\
\hline \multirow{5}{*}{ Subject 9 } & wo Impactor or Support Rotation & 0.778 & 0.855 & 0.725 \\
\cline { 2 - 5 } & Impactor Rot. +10deg & 1 & 0.87 & 0.774 \\
\cline { 2 - 5 } & Impactor Rot. -10deg & 0.111 & 0.812 & 0.783 \\
\cline { 2 - 5 } & Support Rot. +5deg & 0.778 & 0.87 & 0.71 \\
\cline { 2 - 5 } & Support Rot. -5deg & 0.778 & 0.842 & 0.642 \\
\cline { 2 - 5 } & average rotations >0 & $\mathbf{0 . 1 1 1}$ & $\mathbf{0 . 0 1 5}$ & $\mathbf{0 . 0 1 7}$ \\
\cline { 2 - 5 } & average rotations $<\mathbf{0}$ & $\mathbf{- 0 . 3 3 3 5}$ & $\mathbf{- 0 . 0 2 8}$ & $\mathbf{- 0 . 0 1 2 5}$ \\
\hline
\end{tabular}


Table H: Cora scores for the curves of figure 8

\begin{tabular}{|c|c|c|c|c|}
\hline $\begin{array}{c}\text { Ouyang } \\
\text { PMHS }\end{array}$ & Scaled Model & Phase & Magnitude & Slope \\
\cline { 2 - 5 } & wo Impactor or Support Rotation & 0.778 & 0.855 & 0.725 \\
\cline { 2 - 5 } & Impactor and Support Rot. +5deg & 1 & 0.87 & 0.774 \\
\hline \multirow{2}{*}{$\# \mathbf{8}$} & wo Impactor or Support Rotation & 0.6 & 0.846 & 0.725 \\
\cline { 2 - 5 } & Impactor and Support Rot. -5deg & 0.9 & 0.827 & 0.677 \\
\hline
\end{tabular}

2. Quantitative comparisons computing peak force, displacement, slope and area under the curves for figure 6 of the manuscript

Table I : Peak force, impactor displacement at peak force, slope and area under the curves for figure 6 of the manuscript

\begin{tabular}{|l|l|c|c|c|c|}
\hline & & $\begin{array}{c}\text { Peak Force value [kN] } \\
\text { Fmax }\end{array}$ & $\begin{array}{c}\text { Displ. [mm] } \\
\text { at Fmax }\end{array}$ & $\begin{array}{c}\text { Slope [kN/mm] } \\
\text { at Fmax }\end{array}$ & $\begin{array}{c}\text { Area under } \\
\text { the curve [J] }\end{array}$ \\
\hline \multirow{5}{*}{ Subject 3 } & Experiment & 2.81 & 22 & 0.128 & 90 \\
\cline { 2 - 6 } & Baseline & 2.91 & 34 & 0.086 & 96 \\
\cline { 2 - 6 } & Scaled Model & 2.99 & 21 & 0.143 & 100 \\
\hline \multirow{5}{*}{ Subject 4 } & Experiment & 3.00 & 26 & 0.116 & 91 \\
\cline { 2 - 7 } & Baseline & 2.86 & 34 & 0.084 & 93 \\
\cline { 2 - 7 } & Scaled Model & 2.62 & 27 & 0.097 & 99 \\
\hline \multirow{5}{*}{ Subject 5 } & Experiment & 2.16 & 21 & 0.103 & 77 \\
\cline { 2 - 7 } & Baseline & 2.76 & 34 & 0.081 & 95 \\
\cline { 2 - 7 } & Scaled Model & 2.41 & 26 & 0.093 & 82 \\
\hline & Experiment & 4.36 & 18 & 0.242 & 140 \\
\cline { 2 - 7 } & Baseline & 3.29 & 37 & 0.089 & 128 \\
\cline { 2 - 7 } & Scaled Model & 3.85 & 32 & 0.120 & 131 \\
\hline \multirow{3}{*}{ Subject 9 } & Experiment & 3.18 & 16 & 0.198 & 86 \\
\cline { 2 - 7 } & Baseline & 2.31 & 33 & 0.070 & 77 \\
\cline { 2 - 7 } & Scaled Model & 2.62 & 16 & 0.163 & 79 \\
\hline
\end{tabular}


Table J: Variations (\%) of peak force, displacement at peak force, slope and area under the curves for baseline and scaled models vs experimental testing (figure 6 of the manuscript)

\begin{tabular}{|c|c|c|c|c|c|}
\hline $\begin{array}{l}\text { Ouyang } \\
\text { PMHS }\end{array}$ & Curve & $\begin{array}{c}\text { Fmax Variations } \\
{[\%]}\end{array}$ & $\begin{array}{c}\text { Displ. Variations } \\
{[\%] \text { at Fmax }}\end{array}$ & $\begin{array}{c}\text { Slope Variations } \\
{[\%] \text { at Fmax }}\end{array}$ & $\begin{array}{c}\text { Energy } \\
\text { variations }[\%]\end{array}$ \\
\hline \multirow{3}{*}{$\# \mathbf{3}$} & Experiment & & & & \\
\hline & Baseline & -3.8 & -54.5 & 32.9 & -6.8 \\
\hline & Scaled Model & -6.6 & 4.5 & -11.7 & -10.7 \\
\hline \multirow{3}{*}{$\# 4$} & Experiment & & & & \\
\hline & Baseline & 4.7 & -30.8 & 27.2 & -2.5 \\
\hline & Scaled Model & 12.6 & -3.8 & 15.9 & -9.3 \\
\hline \multirow{3}{*}{$\# 5$} & Experiment & & & & \\
\hline & Baseline & -27.7 & -61.9 & 21.1 & -23.3 \\
\hline & Scaled Model & -11.3 & -23.8 & 10.1 & -6.8 \\
\hline \multirow{3}{*}{$\# 8$} & Experiment & & & & \\
\hline & Baseline & 24.6 & -105.6 & 63.3 & 8.4 \\
\hline & Scaled Model & 11.6 & -77.8 & 50.2 & 6.3 \\
\hline \multirow{3}{*}{$\# 9$} & Experiment & & & & \\
\hline & Baseline & 27.3 & -106.3 & 64.7 & 10.6 \\
\hline & Scaled Model & 17.6 & 0.0 & 17.6 & 7.3 \\
\hline \multirow{3}{*}{ Averages } & Baseline & 17.6 & 71.8 & 41.8 & 10.3 \\
\hline & Scaled model & 11.9 & 22.0 & 21.1 & 8.1 \\
\hline & Scaled model/Baseline & 5.7 & 49.8 & 20.7 & 2.2 \\
\hline
\end{tabular}




\section{Appendix 7}

Scaling the 6YO PIPER model results

Irwin's coefficients (Irwin et al., 2002) were computed to scale the response curves of the 6YO PIPER child model (baseline):

- to the weight and size of the PMHS \#8 in Ouyang's setup using a pendulum scaling approach ;

- to the weight and size of Irwin's 6YO in Irwin's setups (pendulum and drop tests).

They are described in the tables below for pendulum tests (Table K) and drop tests (Table L).

Table K: Evaluation of the Irwin's coefficients for pendulum tests to scale the 6YO PIPER child model (baseline) to the Ouyang PMHS \#8 (Ouyang's setup) and to the Irwin's $6 Y O$.

\begin{tabular}{|c|c|c|}
\hline Target & Ouyang PMHS \#8 & Irwin 6 YO \\
\hline Age & 6 & 6 \\
\hline Target mass $M_{t}$ & 20.00 & 20.86 \\
\hline Baseline mass $M_{b}$ & 23.00 & 23.00 \\
\hline $\begin{array}{l}\text { Target effective } \\
\text { mass } M_{t e}\end{array}$ & 10.7 & 10.43 \\
\hline $\begin{array}{c}\text { PIPER baseline } \\
\text { effective mass } M_{b e}\end{array}$ & 12.305 & 12.305 \\
\hline $\begin{array}{l}\text { Pendulum mass } M_{p t} \\
\text { for target }\end{array}$ & 3.24 & 3.89 \\
\hline $\begin{array}{l}\text { Pendulum mass } M_{p b} \\
\text { for the PIPER baseline }\end{array}$ & 3.24 & 3.89 \\
\hline$\lambda_{\mathrm{mt}}=\mathbf{M}_{\mathrm{t}} / \mathbf{M}_{\mathrm{b}}$ & 0.8696 & 0.8476 \\
\hline$\lambda_{\mathrm{mp}}=\mathrm{M}_{\mathrm{pt}} / \mathbf{M}_{\mathrm{pb}}$ & 1.0000 & 1.0000 \\
\hline$\lambda_{\mathrm{ms}}=\left(\mathrm{M}_{\mathrm{te}}+\mathrm{M}_{\mathrm{pt}}\right) /\left(\mathrm{M}_{\mathrm{be}}+\mathrm{M}_{\mathrm{pb}}\right)$ & 0.8968 & 0.8842 \\
\hline$\lambda_{\mathrm{me}}=\lambda_{\mathrm{mt}} * \lambda_{\mathrm{mp}} / \lambda_{\mathrm{ms}}$ & 0.9697 & 0.9586 \\
\hline$\lambda_{\mathrm{k}}$ & 1.0 & 1.0 \\
\hline$\lambda_{\mathrm{V}}$ & 1.0 & 1.0 \\
\hline $\mathbf{R}_{\mathrm{f}}=\lambda_{\mathrm{V}} *\left(\lambda_{\mathrm{me}} * \lambda_{\mathrm{k}}\right)^{0.5}$ & 0.9847 & 0.9791 \\
\hline $\mathbf{R}_{\mathrm{d}}=\lambda_{\mathrm{V}} *\left(\lambda_{\mathrm{me}} / \lambda_{\mathrm{k}}\right)^{0.5}$ & 0.9847 & 0.9791 \\
\hline
\end{tabular}

Table L: Evaluation of the Irwin's coefficients for drop test to scale the 6YO PIPER child model (baseline) to the Irwin's $6 Y O$.

\begin{tabular}{|c|c|c|c|c|c|c|c|}
\hline Target & Age & $\begin{array}{c}\text { Target } \\
\text { mass } \mathbf{M}_{\mathbf{t}}\end{array}$ & $\begin{array}{c}\text { Baseline } \\
\text { mass } \mathbf{M}_{\mathbf{b}}\end{array}$ & $\lambda_{\mathrm{k}}$ & $\lambda_{\mathrm{V}}$ & $\lambda_{\mathrm{mt}}=\mathbf{M}_{\mathrm{t}} / \mathbf{M}_{\mathrm{b}}$ & $\mathbf{R}_{\mathrm{a}}=\lambda_{\mathrm{V}} *\left(\lambda_{\mathrm{k}} / \lambda_{\mathrm{mt}}\right)^{\mathbf{0 . 5}}$ \\
\hline Irwin 6YO & 6 & 20.86 & 23.00 & 1.0 & 1.0 & 0.9070 & $\mathbf{1 . 0 5 0 0}$ \\
\hline
\end{tabular}


The effect of the scaling applied to the 6YO PIPER model results (Figure 4 to figure 6 of the manuscript) is shown on the following figures.

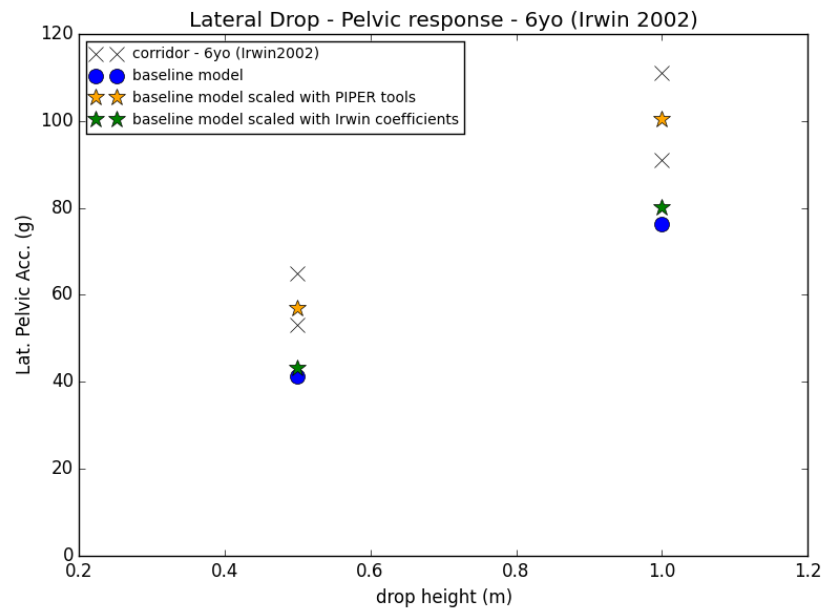

Figure $N$ : Effect of the Irwin's scaling on the sacrum acceleration vs drop height

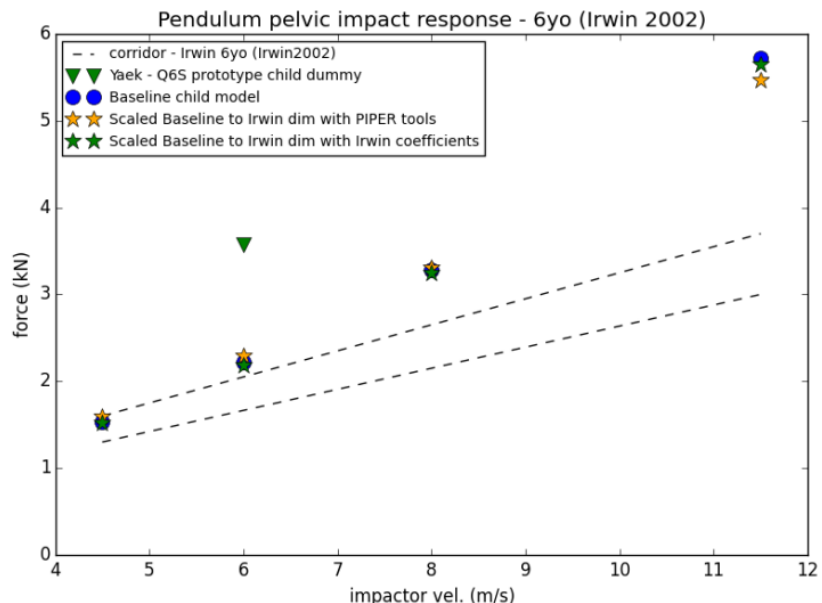

Figure $O$ : Effect of the Irwin's scaling on the pendulum pelvis force vs impactor baseline

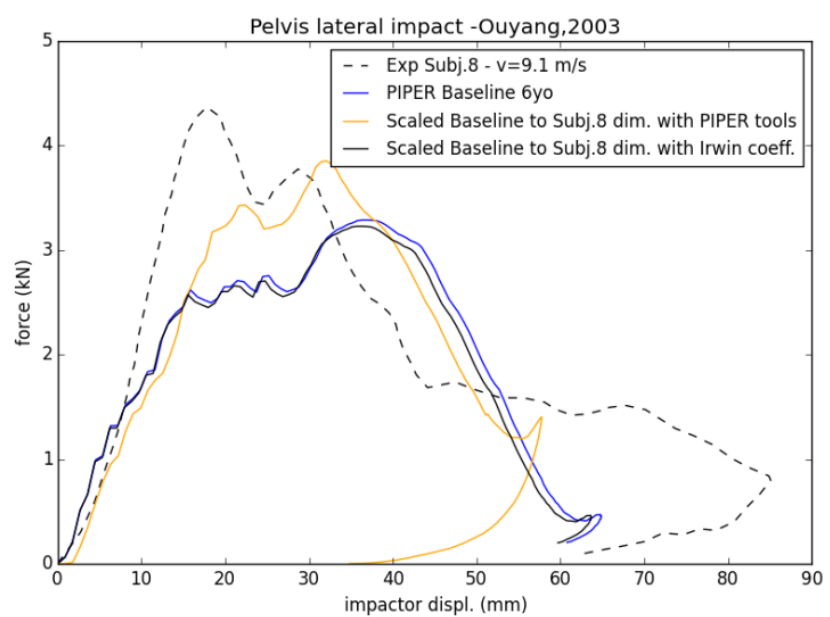

Figure $P$ : Effect on the Irwin's scaling on the pelvic lateral force vs the impactor displacement for the Ouyang 